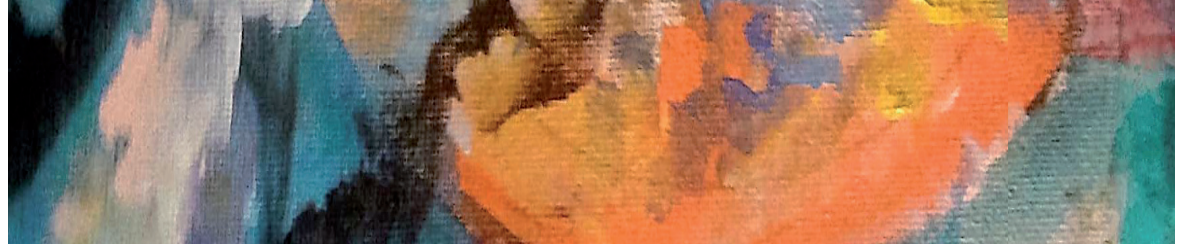

Entreculturas 11 (2021) pp. 36-52 - ISSN: 1989-5097

\title{
BELLEZA Y ATRACCIÓN EN TRADUCCIÓN LITERARIA
}

\section{Beauty and Attraction in Literary Translation}

\author{
(1) Natalia Arregui Barragán \\ Louis Jolicœur \\ Universidad de Granada / Universidad Laval (Canadá)
}

Recibido: 29 de septiembre de 2020

Aceptado: 17 de diciembre de 2020

Publicado: 27 de febrero de 2021

\begin{abstract}
The approach to literary translation proposed here relies on three concepts: beauty, generated from ambiguity; attraction, produced on the reader-translator by the source text; and the effect caused by the source text and the translated text. Attraction is linked to what we may deem beautiful, or to what we could call the beauty effect; and it is what triggers the movement towards translation. The reader-translator must thus be seduced by the text while at the same time trying to make up for the absence generated by it. As for the effect, that the translator must identify in order to eventually reproduce it, it is linked to the internal cohesion of the text, to the marks left by the author and to the ambiguity inherent in the aesthetics of the text. In other words, the effect of the text is what the translator should yearn to reproduce, after finding his or her way.
\end{abstract}

KEYWORDS: literary translation, beauty, attraction.

\section{RESUMEN}

La noción de traducción literaria que les proponemos en estas páginas se cimenta en tres conceptos: la belleza, definida por su relación con el vacío y lo ambiguo, la atracción que ejerce el texto origen sobre el lector-traductor y el efecto provocado tanto por el texto origen como por el traducido. La atracción, estrechamente relacionada con lo que nos gusta, con lo que podríamos denominar el efecto de lo bello, es considerada en estas páginas como el motor de la traducción, en cuanto que el lector-traductor debe ser seducido por el texto que va a traducir, al tiempo que intentar colmar la ausencia que lo interpela. En cuanto al efecto, que hay que saber aprehender si queremos reproducirlo en la traducción, está unido a la coherencia interna del texto, a las huellas del autor, a la ambigüedad inherente a la estética del texto. Resumiendo, el traductor debe consagrase al efecto que produce el texto, una vez haya encontrado su vía y su voz.

PALABRAS CLAVE: traducción literaria, belleza, atracción. 


\section{BELLEZA Y ATRACCIÓN EN TRADUCCIÓN LITERARIA}

Gustavo Adolfo Bécquer manifestaba que el espectáculo de lo bello, en cualquier forma que se presente, levanta la mente a nobles aspiraciones y qué aspiración más noble para un traductor que traducir la belleza de un texto. Esa belleza inteligible y sin reflexión, que diría André Maurois, esa belleza que junto a la bondad y la verdad iluminaron el camino de Albert Einstein y le infundieron valor para enfrentarse a la vida.

\section{LA BELLEZA}

Conviene reflexionar sobre la belleza en sí misma -sobre todo en cuanto a motor de la atracción, para nosotros concepto esencial en el proceso de traducción-, antes de interrogarnos sobre la traducción literaria y la posibilidad de traducir bellamente lo que encontramos bello. Debemos intentar circunscribir esta belleza, su sentido, su origen, su poder, su dinámica, si queremos dialogar sobre la belleza de un texto y sobre la belleza de su traducción después.

Todo lo que leemos, como todo lo que vemos, oímos, degustamos o sentimos se relaciona ante todo con una cosa: el placer que experimentamos cuando algo nos gusta o el rechazo que sentimos cuando no lo hace en absoluto. Idealmente lo que nos gusta, será bueno, será bello.

Todos asociamos la idea de belleza con las personas, las ciudades, los paisajes, con películas, músicas, lienzos, libros, una escritura. A veces, sabemos en seguida por qué juzgamos una cosa o una persona bella: encontramos en ella criterios precisos, desarrollados tiempo atrás, adoptados de forma más o menos consciente, más o menos individual. Otras veces no tenemos tan claro por qué la cosa o la persona nos parece bella, simplemente nos sentimos atraídos sin una razón particular. O quizá, queremos encontrar bella la cosa o a la persona porque lleva asociado un elemento nuevo, interesante, diferente. $Y$ aunque a veces dudamos en reconocer la belleza, siempre estamos, por el contrario, preparados para afirmar que una cosa o una persona carecen de ella.

Así, la belleza nos acompaña constantemente, nos seduce, nos estimula, nos transporta. Estemos donde estemos, en cualquier circunstancia, sea cual sea el entorno cultural, geográfico o plástico que nos rodee, buscamos la belleza, nos maravilla, le rendimos homenaje, deploramos su ausencia y nos compadecemos de quienes están privados de ella.
Por otro lado, la noción belleza es frágil y elástica: varía con el transcurso del tiempo, a veces incluso de un año a otro, toma diferentes formas según el lugar, la mirada de unos, las costumbres de otros, sin contar con que en un mismo individuo evoluciona en el curso de una vida, al contacto con diferentes personas y realidades. Pero hagamos lo que hagamos con este concepto, digamos lo que digamos, resurge una pregunta que es indispensable a la hora de traducir: ¿por qué es bello?

Indaguemos un poco en la naturaleza misma de la belleza observando algunos aspectos relativos al léxico.

La palabra precioso evoca cierto misterio que, a primera vista, no se encuentra en sus correspondientes francesas: beau, joli, superbe, sublime, ravissant, magnifique, merveilleux, splendide, etc. De hecho, en su alusión a algo de gran valor que suscita la admiración y que hay que proteger celosamente, podríamos decir que la palabra precioso asocia lo bello al destello, a la riqueza, al hechizo creado por ese algo. Quizá sería mejor hablar de objeto de mucho valor, puesto que es cierto que la palabra précieux no se traduce por precioso, problema sobre el que volveremos posteriormente; pero el paralelismo etimológico entre las dos palabras es tan palpable que la deriva semántica que ha sufrido la palabra precioso no le resta un ápice a la hipótesis.

Así pues, si lo bello se asocia a lo que tiene valor, nos conduce por consiguiente a lo que tradicionalmente se considera una de las cosas más valiosas: un tesoro. De aquí surge el aspecto más interesante: ¿qué hay más misterioso que un tesoro?

Es cierto que la lengua española dispone de otras maneras de describir con distinta intensidad lo bello: bonito, lindo, guapo, hermoso, magnífico, maravilloso, espléndido, etc. Palabras en las que, como en las francesas que acabamos de citar, la idea de misterio estaría ausente. Por lo tanto, si encontramos la palabra precioso entre las que designan lo bello, no puede ser ni por azar ni por capricho. ¿Acaso la lengua no inventa, no toma prestado, no transforma por razones de precisión y eficacia?

En vez de intentar saber por qué una palabra como precioso existe -cuestión cuando menos abstracta- vamos a ver si las demás palabras españolas y francesas enunciadas 
están efectivamente desprovistas de cualquier halo de misterio. Para ello, volvamos a la traducción de esta palabra.

Exceptuando la expresión pierres précieuses, que se traduce por piedras preciosas, pocos son los casos en los que précieux se traducirá por precioso. Un tableau précieux, por ejemplo, será un cuadro valioso y un ami précieux, un amigo apreciado. Traducir estas expresiones utilizando precioso sería simplemente incurrir en un falso amigo. De todas formas, esta observación no invalida de modo alguno el análisis. Alejándose -derivando- de su significado original (que el francés ha mantenido) la palabra precioso se convierte en otra cosa, pero conserva el recuerdo, la marca, la evocación de ese significado original, es decir, preserva toda la carga etimológica y la connotación.

Además, aunque la lengua francesa no disponga de una palabra que englobe lo bello y el misterio aludiendo a lo precioso, sí tiene varias que provienen de otras fuentes y que se asocian hoy en día esencialmente a lo bello. La palabra merveilleux, por ejemplo, antes de ser únicamente un sinónimo de magnifique, significó durante mucho tiempo (y lleva en ella esta carga de significado) étonnant, incroyable, incluso épouvantable (para Montaigne), sin contar con el significado de surnaturel aún actual en literatura. En cuanto a una palabra como ravissant, por dar otro ejemplo, aunque se limita generalmente a designar lo bello, evoca etimológicamente el delirio, la exaltación, la emoción, el éxtasis, el arrobamiento. Así pues, ¿qué sugieren las palabras étonnement y exaltation sino misterio?

Consideramos pues legítimo, a pesar de las apariencias y las distinciones hechas entre el francés y el español, proponer que lo bello, sea aludiendo a lo precioso o a un algo inaccesible, está asociado al misterio. Y esto tanto en francés como en español, sin hablar de otras lenguas, ya que el inglés no sería diferente.

Aunque esta constatación es esencial para la comprensión del concepto belleza en el mundo actual, debemos constatar, sin embargo, que se trata de un problema por el que la lingüística, sin hablar de la filosofía ni siquiera de la literatura, no se ha interesado mucho estos últimos años. ¿Nos debería sorprender? El misterio de la belleza, la utopía de la belleza, la belleza como enigma, son temas de poca actualidad en estos días en los que a menudo se la asocia a tendencias, modas o a veces a la muerte - una muerte no obstante sin substancia, en la medida en la que sólo es presentada a través de los medios, de la publicidad, de expresiones artísticas inmediatas y superficiales-. Y, de este modo, la belleza, tanto si se asocia a las modas como a una muerte privada de substancia, está abocada a la insignificancia, nunca al conocimiento. Lo que no contribuye, reconozcámoslo, a la causa del arte en general.

Quizá sería incluso más grave perpetuar el silencio en torno a la cuestión, ya que sea lo que fuere de este debate, sean cuales sean las posturas adoptadas, existe una posibilidad de reflexión totalmente contemporánea sobre la lengua y la literatura; reflexión por otra parte estrechamente ligada a los problemas de la traducción literaria, incluso de la traducción general, así como a las soluciones de estos mismos problemas.

El enigma de la belleza puede ser quizás una vía abierta a un punto de vista más profundo y dinámico en relación al texto, también más útil para los propósitos de la traducción.

Desde finales del siglo XIX, no obstante, podría decirse que Occidente ha perdido interés por acercarse al conocimiento, a la verdad, a través de la belleza.

Se la ha excluido de los aspectos fundamentales de la sociedad, ha sido confinada a una zona sombría, relegada a lo efímero. Sin embargo la belleza es una forma simbólica que no se dirige hacia la insignificancia, proporciona más bien, por medio del enigma que la constituye y del mito del que proviene, una clave esencial para la interpretación del mundo.

El proceso de desmitificación en el que estamos inmersos es, sin duda, el que ha sustraído a la belleza su fuerza dinámica, su valor de verdad. Es cierto que hay nuevos mitos que sustituyen a los antiguos, pero incluso así, más que de mitos, ¿no habría que hablar de modas, de tendencias? Y si se trata fundamentalmente de mitos, tenemos que constatar que su vida es breve y que, en consecuencia, no pueden imponerse al imaginario colectivo, ni actuar a partir de este imaginario colectivo, sobre la sociedad. Difícilmente puede 


\section{BELLEZA Y ATRACCIÓN EN TRADUCCIÓN LITERARIA}

Entreculturas 11 (2021) pp. 36-52

la belleza seguir creando una continuidad en el sistema, a través de mutaciones de formas y de significados, si el mito queda paulatinamente postergado a la Historia.

Así pues, es esencial buscar el valor dinámico de la belleza ya que también es el seno donde la literatura -y por tanto la traducción literaria- adquiere un significado mucho más vasto. Si la belleza está en la base del conocimiento y de la intervención, si por mediación de la duda y del enigma la belleza se convierte en un motor, el lenguaje simbólico puede convertirse en la expresión de la creatividad, en la enunciación de la verdad, en el principio de un intercambio que trasciende lo inmediato y la unicidad, de manera que, como dirían los estructuralistas, las partes combinadas constituyen un todo superior a la suma de las partes.

El interés de esta visión de la belleza fundada sobre el enigma y la duda reside en que se articula con el concepto atracción que exponemos en estas líneas. De la misma manera que los vacíos del texto son los que permiten que el lector, por el lugar que se le ha dejado, se introduzca en él, sienta su dinámica e interactúe después con el autor (para finalmente traducirlo), podemos decir que lo que hace posible lo bello es el enigma, y esquemáticamente, que lo que hace posible el proceso de traducción, a través de la falla, es la belleza y la atracción que hacia ella sentimos.

Hablamos, indiscutiblemente, de una belleza iniciática, de una invocación del mito ya que la belleza y el mito tienen en común la relación con lo oculto, lo desconocido, una fuerza enigmática que nos cautiva y nos impulsa a actuar. Esta fuerza es una visión hacia adelante, tracción irrevocable y casi exponencial, hacia otra cosa, hacia un más allá que nos atrae pero que no puede alcanzarse y que continuará atrayéndonos precisamente por su carácter inalcanzable. Esta fuerza también es la creación de un significado suplementario, de un elemento que viene a añadirse a los demás, que depende de ellos, e incluso es su fruto, siendo al mismo tiempo algo nuevo, impensable sin la estructura que lleva a su creación. Esta fuerza, que podríamos denominar la fuerza de lo bello, mana de la propia estructura de lo bello, esta estructura que permite que el todo sea superior a las partes, aún siendo su prolongación.
Aunque este concepto de belleza está relacionado manifiestamente con la visión estructuralista, hay que reconocer que también tiene, como cualquier mito, una función, un resultado: la dinámica de la intervención del lector por los intersticios del texto, intervención posible por la atracción creada y desarrollada a partir de la belleza. Encontramos por lo tanto, la estructura y la función en el núcleo de la lectura activa, de la traducción después, curso natural del proceso.

Pero antes de centrarnos en la repercusión de la belleza sobre la traducción volvamos al propio concepto y a su lugar en el imaginario que lo ha creado, que lo alimenta y del que es tributario.

Podríamos señalar que el siglo XX ha restringido, en buena parte, la belleza a tendencias y modas -contrariamente a la época romántica, por ejemplo, que desarrollaba la idea, más dinámica por esencia, de una belleza sublime, soberana y total, en la que un delirio estético como el del amor-pasión no quedaba del todo consagrado si no llegaba al más allá-. Hemos visto igualmente que, a veces, se asocia a la muerte, pero a una muerte más ligada a los medios que a una substancia real portadora de sentido. Así pues, la alusión a la muerte en el discurso actual sobre la belleza (y en el trato otorgado hoy a lo bello en semejante marco mediatizado y efímero) no solo reduce mucho su trascendencia, sino que también contribuye a que el propio concepto se encuentre totalmente desmitificado.

De este modo, más que una relación real y dinámica entre la muerte y la belleza, el resultado se presenta como una visión estética de la muerte. Pensemos en el cine: la violencia estética, la belleza del peligro, la muerte en directo, el voyerismo legitimado, el atractivo (y acto seguido la eliminación) del tabú, etc. Ahora bien, si es cierto que esta alusión a la muerte en sí misma puede constituir una apertura hacia un saber, al menos hacia un deseo de saber, el efecto se pierde desde el momento en el que nos sirven una impresión aseptizada, una muerte de salón o de telenovela, una belleza consumida con avidez y desechada con rapidez, un amor anónimo y repetitivo, un misterio de pacotilla en el que lo desconocido es como una máscara, simbólica pero escindida del mito. 
La belleza vista como un concepto, la imagen limitada a la fotografía, la música restringida a la ausencia de ruido, la literatura reducida a la narración. De tal manera que poco queda del arte como encarnación de una búsqueda, de un juego (pensemos en Schiller: "El hombre sólo es enteramente hombre cuando juega ${ }^{1}$ ”), o incluso más importante, de un vehículo.

Esta belleza de forma, exangüe y amitificada es la impresión volátil, la velocidad, la discontinuidad. La estética moderna ha fragmentado la belleza quitándole su carácter global, lo que permitía hacer de ella un todo dinámico. Aunque la modernidad ha alterado así el poder de la belleza, esta misma modernidad ha permitido fisurar el objeto, entreabrirlo, ofrecerlo a la participación de otros. En consecuencia, si por una parte se ha perdido el carácter global de la belleza, queda otra apertura, otra vía: la falla, la ausencia. La revolución que agitó los cimientos literarios, sobre todo a partir de los surrealistas, o la que conoció la música (con compositores como Schönberg, precursor de la transición a la atonalidad, que se dedicaron a fragmentar la melodía y a diferenciarla de la gama diatónica), o la pintura, con los cubistas por ejemplo, también son reflejo de la modernidad.

De este modo podríamos decir que la fragmentación de la belleza se encuentra en cierta manera compensada por la del objeto, dos nociones que no deben confundirse. De hecho, aunque la fragmentación de la belleza (su minimización a un estado estereotipado, intelectualizado, que hay que contemplar, incluso analizar, más que aprehender e injerir) está sin duda condenada a la esterilidad, la del objeto le ha dado un nuevo impulso al arte, vivificándolo al exponerlo a la intervención humana. Y si cierto exceso en la idea de fragmentación del objeto puede ser tan estéril como el exceso de fragmentación de la belleza, resulta interesante observar, en el arte, la emergencia de un movimiento de retorno hacia una posición más global.

1 Friedrich Schiller, Cartas sobre la educación estética del hombre. Decimoquinta carta. http://www.antorcha.net/biblioteca_virtual/filosofia/schiller/15.html
Sintetizando, una visión nueva que une el moderno instrumento de la falla, de la ausencia, del lugar del otro con una visión global del mundo.

El filósofo italiano Stefano Zecchi se expresa en estos términos sobre la fragmentación de la belleza:

La estética moderna, fruto del pensamiento hegeliano, es vista como un concepto, una lógica, y en consecuencia como una verdad parcial, incompleta, que sigue dependiendo de una forma superior de saber que es la única que le puede conferir la base teórica de su auto-comprensión ${ }^{2}$ (1990:11).

Lo que explica Zecchi, siguiendo los pasos de los estetas alemanes del siglo XVIII (Schiller, Hölderlin, Novalis) y retomando algunas ideas de Umberto Eco, es que el Occidente moderno al privar a la belleza de su significado y de su dinámica, la ha desposeído del marco teórico que permite su comprensión y su utilización. Al convertirse la belleza en objeto de consumo asubstancializado ${ }^{3}$, no puede ser explicada ni integrada en un proceso de interacción entre otro -humano, objeto-y ella misma.

Así pues, si aceptamos volver a los estetas alemanes (y al hacerlo, a los griegos, con Platón a la cabeza) y ver la belleza como un todo dinámico y una verdad en sí misma, si además concebimos el mito al que está asociada como un significado utópico pero generador de sentido, obtenemos un símbolo, fuente de interrogación más que de explicación, que, por plantear más que por explicar, se inscribe en la Historia.

La belleza, vista como un mito que prolonga el efectobello en el tiempo y lo inscribe en la Historia, es el mismísimo núcleo del símbolo. Para Goethe, la invocación del mito es la búsqueda del arquetipo de lo bello. En el campo

2 La traducción es nuestra.

3 Jean Paul Sartre habla de transubstanciación y de degradación de las pasiones del artista desde el instante en el que ofrece su arte a otros en la obra ¿Qué es la literatura? traducción de Aurora Bernárdez, Madrid, Losada, 2003, p.56. 


\section{BELLEZA Y ATRACCIÓN EN TRADUCCIÓN LITERARIA}

Entreculturas 11 (2021) pp. 36-52

de la lengua, esto da, por ejemplo a la metáfora, un valor muy superior al que reviste cuando está desprovista de un marco mítico. Parece que se puede encontrar en este pensamiento una tentativa de unir lengua y mundo, lo que manifiestamente va contra todo acto de desmitificación. Este tipo de enfoque, asociado a la apertura manifestada con la fragmentación del objeto, atenuaría quizás el riesgo de imponer sistemáticamente el pensamiento a la lengua, de negar la metáfora o de rebajarla a un ingenio estrictamente relativo al lenguaje, y de reducir el mito a la mitología -en el sentido restringido de un repertorio etnológico de ritos y costumbres de una comunidad-.

Al desmitificar, se propone lo abstracto, es decir, que se vacíe el símbolo. Al desmitificar, sólo se lee la metáfora como una transposición de la palabra verdadera (literal), despojándola así de cualquier valor intrínseco más allá de la cadena del discurso. Sin embargo, el valor principal de la metáfora es precisamente el más allá del discurso inmediato, o la relación entre el ser del lenguaje y la experiencia del mundo (del afuera, diría Foucault ${ }^{4}$ ).

Jacques Lacan, por su parte, explica que la metáfora es una tentativa de pasar por un símbolo para alcanzar el objetivo. Como el disfrute es imposible, la metáfora es el paso por el lenguaje, en lugar del paso al acto, es lo social más que la pulsión pura y la muerte ${ }^{5}$.

Lo bello considerado como un motor, un símbolo, una invocación, interesante acepción en el campo que nos ocupa.Y como nuestra época está constituida por un torbellino de corrientes, esta tiene un espacio, sobre todo porque ya está admitido que el arte es móvil, maleable, incompleto y abierto a la intervención de cualquiera [¿̇no repetía Oscar Wilde que es la naturaleza la que imita al arte? Y Balzac respondería: la misión del arte no es copiar la naturaleza sino expresarla (1931); Paul Ricœur por su parte proponía: “La tragedia sólo

4 Michel Foucault, El pensamiento del afuera, traducción de Manuel Arranz, Valencia, Pre-textos, 2000.

5 Jacques Lacan. Écrits I, París, Seuil, 1966. imita la realidad porque la recrea por medio de un mûthos, "una fábula”, que toca su esencia más profunda"(2001:108)].

El arte no es soberano, pero la belleza sí lo es: no puede ser conquistada ni dominada, es el lenguaje simbólico de la estética del mundo, y connota el tesoro, el misterio, el enigma. El símbolo transforma un fenómeno en idea y una idea en imagen, y la idea siempre está activa e inaccesible en la imagen y, aunque puede decirse en todas las lenguas, permanece indecible. Así pues, el efecto-bello funciona, nos interpela, nos impulsa y permite que se establezca un lazo entre lo que es considerado bello y el o la que lo encuentra bello, porque la idea está ahí. Es la función inaccesible de la idea lo que le da a la belleza su existencia y su fuerza.

"Es tanto más bonito cuanto inútil” le hace decir Rostand a Cyrano, a lo que incluso podríamos añadir: cuanto imposible. O, más cercano a nosotros y a la teoría literaria, también podríamos pensar en Roland Barthes: "La inutilidad misma del texto se convierte en útil” (1974:40), ya que la belleza se sustenta en la distancia que hay que recorrer para desarrollar una idea, en el esfuerzo que se realiza para explorar la oscuridad en busca de un misterio, o para cavar con el objetivo de alcanzar el preciado tesoro. Este tesoro ejercerá tanto más poder de atracción cuanto más inaccesible sea, más inabarcable, más difícil de poseer, ya que la fuerza de la belleza reside, hay que insistir, en el proceso más que en el resultado.

Esta perspectiva nos aleja mucho de autores como Marguerite Duras, al menos cuando afirma en una nota a pie de página en su novela El amante de la China del Norte: "La belleza no hace nada. No mira. Es mirada” (1991:60).

Pero no es del todo cierto. Proponíamos unas líneas más arriba que aunque la estética moderna ha fragmentado la belleza alterando así su cohesión y su dinamismo, también ha permitido fragmentar el objeto, entreabrirlo, ofrecerlo para que otro participe. De este modo, aunque la cohesión y el dinamismo han sido desalojados de la belleza, la apertura que se ofrece a través de las fisuras del texto reintroduce el dinamismo en la forma estética.

Además, el caso de Marguerite Duras resulta muy interesante en este contexto ya que su escritura en cierto modo 
contradice su propio comentario: la autora, mediante un estilo lento y segado que crea innumerables ausencias, y que a veces hace gala de un lirismo en el que la belleza no es ni estática ni cerrada, ofrece al lector un lugar muy privilegiado y dinámico. Tanto que resulta difícil imaginar que la belleza "no hace nada, no mira, es mirada".

Hay que indicar al respecto que los traductores de las obras de M. Duras, reunidos en 1987 en un coloquio en Arles, se mostraban de acuerdo al decir que la dificultad y el interés de traducir a $M$. Duras residía en que había que implicarse en el texto, dialogar con la autora: establecer con el uno y la otra un lazo estrecho. En primer lugar y ante todo, localizando la ambigüedad y reconstituyéndola después. Algunos hablaban literalmente de "ambigüedad que hay que reproducir" (Marianne Kaas, Países Bajos); otros sugerían "buscar una sensación equivalente" o "respetar y reproducir cierta imprecisión” (Jukka Mannerkorpi, Finlandia); "buscar una clave, es decir la gama, el nivel de palabras que había que emplear a lo largo de la traducción", después "encontrar a pesar de todo un equilibrio" y "tener en cuenta una suma y los factores de una suma" (Leonella Prato Caruso, Italia); "realizar una asonancia análoga en otro lugar” (Ilma Rakusa, Suiza); incluso "traducir también el vacío" y "crear en el lector la misma impresión de nolugar, de no-dicho, de una escritura de vacíos" (Ingrid Sagranek, Serbia) ${ }^{6}$.

Todos estos comentarios apuntan a una fragmentación de la obra que permite la participación del lector-traductor en una escritura en la que la belleza, particularmente para el traductor, no puede ser inmóvil; y esta fragmentación es la que articularemos a la reproducción del efecto ${ }^{7}$ en la traducción.

6 Actes des quatrièmes assises de la traduction littéraire, Arles, Actes Sud, 1988, pp. 89-107.

7 Definir en pocas líneas este concepto es harto complicado. No obstante, sabemos que el texto traducido deber ser intrínsecamente coherente y eficaz y que el traductor debe velar por que esta coherencia y esta eficacia sean lo más semejantes posible a las del texto origen. $\mathrm{Si}$ consigue esta correspondencia, habrá reproducido el efecto, es decir, en el corazón del sentido y más allá de este, lo que queda.
A este respecto pensamos también en Juan Carlos Onetti quien consigue que el lector participe en el relato no porque emplee el pronombre tú o vosotros-ustedes, como los escritores del Nouveau Roman, sino porque dirige la mirada del lector (procedimiento de focalización), haciendo de éste un personaje de la novela por la posición que le atribuye ${ }^{8}$. En este sentido también, podríamos evocar a Julio Cortázar quien afirma que el lenguaje debe ser el hombre, no solo su expresión, única forma de permitir que la obra viva abriéndose a otros, dejando que la habiten.

Aunque esta reflexión se puede aplicar a la literatura contemporánea en su conjunto, refleja particularmente la actitud de numerosos autores latinoamericanos, para quienes los vacíos y las ausencias del texto suplantan frecuentemente la cronología de los acontecimientos así como a estos mismos. Para ellos, la mirada sobre las cosas supera también las cosas en sí mismas, como el movimiento del ser supera el movimiento del cuerpo. En esta literatura, donde lo que es paralelo a la vida transciende la propia vida, y en la que más allá de la sicología, lo que cuenta es la posición existencial, autoreflexiva, fenomenológica, el motor lo constituye el ser antes que la palabra. En estas páginas nos referimos precisamente a este motor, que debe hallarse en todo traductor de obras literarias9.

Puesto que más allá de la Historia y de la evolución de la belleza, el aspecto en el que en este artículo queremos incidir es el de motor, concepto que propicia la atracción. También podríamos añadir la noción poder. De hecho, si nos interesamos por la belleza, será difícil abstraerse al poder ligado a ella, y al deseo o a la quimera de ostentarla (en uno mismo o en otro que creemos o deseamos poseer).

Beauty is in the eye of the beholder, dice el adagio. Es decir, en la mirada de la persona que ve la belleza, desde luego, pero ¿no evoca también la etimología la idea de la

8 Louis Jolicœur trata esta cuestión de la focalización en el prefacio de su traducción de la novela Los Adioses de Onetti (Les adieux, París, Christian Bourgois, 1985).

9 Esta visión latinoamericana de la literatura es tratada por Louis Jolicœur en el prefacio de su traducción de la novela El pozo de Juan Carlos Onetti (Le puits, París, Christian Bourgois, 1985). 


\section{BELLEZA Y ATRACCIÓN EN TRADUCCIÓN LITERARIA}

persona que la posee? Así pues, ¿de quién se trata?: ¿de quien la encarna, o de quien mira? En el adagio se sobreentiende que es la que mira. De acuerdo, pero ¿mirar es poseer? ¿No es ante todo desear, querer poseer y al hacerlo, conceder parcialmente que no se posee? Es innegable que podemos poseer y desear al mismo tiempo y que mirar puede significar también, en cierta medida, poseer. Pero basta con pensar en la religión, en el amor romántico, o incluso en el juego (en cualquier impulso fruto de la evocación de una virtualidad) para ver hasta qué punto es la atracción del poder más que su posesión lo que constituye un motor.

El poder, parte intrínseca del concepto belleza, es otro aspecto que debemos considerar. Precisemos no obstante que hablamos de un poder cuyo interés no radica en su resultado (ni en todo lo malo ligado a él) sino en su origen, en lo que lo alimenta constantemente, es decir: el deseo del poder, un deseo que contribuye al efecto-motor indispensable en el proceso de traducción.

De este modo, como si de un tesoro se tratase, la belleza nos atrae y nos estimula, suscita nuestro deseo.

Así pues, el principal anhelo del traductor es sentir lo bello e intentar reproducirlo después. Pero, ¿hace falta algo bello para poder traducir? Está claro que no, los ejemplos son numerosos tanto para demostrarlo como para recordarnos la realidad de una profesión sometida a las mismas exigencias que las demás: la ley del mercado y la necesidad de ganarse la vida.

Precisemos de entrada que estos comentarios no son en absoluto una crítica a la traducción en serie de superventas y de otras obras de consumo rápido y de duración efímera. Sin embargo, es cierto que aunque el objeto de nuestra reflexión es la belleza en tanto entidad que posee la apertura necesaria para una interacción entre el que mira y lo que es mirado, cabría preguntarse en qué medida esta simplificación aporta algo a la problemática de la traducción, ya que si podemos observar objetivamente que lo no bello dinamiza poco y tiene escaso efecto, nos debería permitir concluir que difícilmente puede su traducción ser de otra manera. Así pues, y contra todo pronóstico, diremos que la traducción de superventas puede alimentar nuestra reflexión pero sólo en un caso: ese en el que el traductor in- tenta hacer bello lo no bello, cavando un pozo de misterio en lo que es liso como una tabla, dando así una substancia (la suya) a lo que carecía de ella.

De forma general, las razones por las que un traductor puede querer mejorar un texto son muchas y variables: mala comprensión del mismo; conocimiento escaso del autor, de su lengua, de su cultura o de su época; etnocentrismo, prejuicios sociales, raciales, religiosos, sexuales; atracción demasiado intensa hacia el texto, o hacia el autor, que causan ceguera o un deseo de mímesis con el texto; deseo de exhibirse por encima del autor traducido; políticas editoriales, etc. Numerosos escollos que podrían ser objeto de un profundo estudio. El caso particular de la traducción de superventas aporta sin embargo un elemento de reflexión suplementario: la cuestión de la subjetividad de lo bello y en corolario, el derecho a decretar lo que es bello, a distinguir lo bello de lo no bello. Aunque estas cuestiones no nos conciernen directamente, deben no obstante ser consideradas puesto que están relacionadas con el lugar que ocupa lo bello en nuestras vidas y en la Historia, así como con el papel del traductor en el proceso comercial y editorial de la obra ya que se sirven del muy resbaladizo terreno de la ideología ${ }^{10}$. Terreno que no podemos ignorar ni siquiera en el núcleo de la traducción.

$\mathrm{El}$ interés del concepto belleza, para el objetivo de este análisis, se sitúa esencialmente en la dinámica establecida entre los dos extremos del proceso de traducción, es decir, en la disyuntiva entre el efecto que hay que sentir y el efecto que hay que reproducir. No obstante hay que aceptar, como acabamos de ver, que esto no puede hacerse al margen de nociones como poder e ideología. Además, es el momento de añadir que esta dualidad entre dos efectos que hay que hacer corresponder es arriesgada. De hecho, pese a que el traductor se siente a menudo solo, libre y sin juez ni ley frente al texto que tiene que traducir, corre un riesgo, quizá más sutil aún en ausencia de elementos coercitivos aparentes, pero más grave puesto que está representado por la pro-

10 Georges Mounin presentó de forma muy clara la cuestión de la subjetividad de la belleza, así como su incidencia en la traducción a través de la Historia, en su conocidísima obra Les belles infidèles (París, Cahiers du Sud, 1955). 


\section{Natalia Arregui Barragán y Louis Jolicœur}

Entreculturas 11 (2021) pp. 36-52

pia posterioridad: el riesgo de traicionar a un autor, incluso a generaciones de lectores. Sin contar con otro peligro más inmediato que también lo acecha: el riesgo de la belleza.

Para Kant, lo bello, intensificación de la vida, unifica nuestras facultades representativas (sensibilidad, imaginación, entendimiento), mientras que lo sublime, trascendencia de lo bello, es la crítica de la existencia. Son definiciones en las que el aspecto asociativo y dinámico de la belleza queda manifiesto. Y en las que la belleza, en absoluto pasiva, requiere exigencia y, por lo tanto, conlleva riesgo ${ }^{11}$. (Claro está, podríamos ir más lejos y pasar de la estética a la ética y ver lo bello como símbolo del bien moral, tema completamente al margen de las cuestiones que aquí debatimos).

El riesgo de la belleza es el riesgo de perderse en ella, o si la dejamos atrás, de caer en la melancolía del retorno, en el spleen del después, en la fría e inevitable aceptación de que la belleza no es sino un momento de plenitud, tanto más estimulante cuanto breve, precedido y prolongado por el vacío propio de lo no bello, ya que lo bello sólo lo es porque antes y después no lo es.

Esta belleza fuente de pulsiones y deseo de expresión, frágil y efímera que late ahí donde se vive brevemente el éxtasis, el hechizo, la armonía cósmica, y que hacía que Goethe dijera: “ipárate, eres tan bello!”, esta belleza que bien podría estar en el origen de la palabra, sí, nadie lo duda, constituye un riesgo, un peligro. Por su carácter todavía-no-presente, utópico, por el placer en cierta medida epicúreo (en el sentido de un placer que induzca al conocimiento y a la acción ligado a ella), por el acuerdo en el que forzosamente debe fundarse, por la tensión que genera, la aspiración que encarna, la belleza no puede sino molestar. Es posible que este sea el germen del debate desencadenado a través de los siglos,

11 Aunque Kant parece abrir la puerta a una visión dinámica de la belleza, afirma sin embargo que esta no conlleva en absoluto acción (Le jugement esthétique, París, Presses Universitaires de France, 1966, p.2). Quizás ahí esté el reflejo del pensamiento de Kant sobre la ética de la belleza; pensamiento que se aleja bastante de la tesis que aquí presentamos. Subrayemos por el contrario que la crítica sobre la fragmentación de la belleza expuesta unas líneas más arriba manifiesta tener puntos en común con las palabras de Kant sobre la sensibilidad unida a lo bello. ya que estética y ética se confunden a menudo, o lo que es lo mismo, se oponen con saña. Pensemos en esos libros de poesía demasiado desbocada, de impulsos demasiado laxistas o de prosa inconveniente, colocados bajo el dedo acusador del clero, de un régimen, o revisados y corregidos en traducciones respetuosas con la ética.

Así pues, lo interesante de este riesgo es su función que, más allá de lo social, se convierte en un símbolo siempre múltiple: el lenguaje de la traducción estética del mundo.

Por lo tanto, riesgo necesario y bello, riesgo de una belleza siempre en movimiento, que sólo se apoya en la fuerza del mito, en el enigma, para permitir el acceso al símbolo. Ello constituirá el concepto atracción y se articulará, con la noción belleza, a un punto de vista que privilegia el efecto (fruto de la conjunción forma-contenido) sobre la intención, el ritmo sobre la apariencia, el resultado sobre el concepto.

Teniendo en cuenta que lo bello es un riesgo no sólo sobre el plano ideológico sino también en sí mismo, en gran medida porque está intrínsecamente ligado a la falla y al enigma, estudiemos ahora con más detenimiento esta unión e intentemos ver en qué nos permite acercarnos al efecto que analizamos en estas líneas.

Falla, enigma, vacíos, intersticios del texto, pueden ser designados de otra forma, de una manera más útil para el propósito de la traducción: ambigüedad. Es lo que el traductor debe esforzarse por reproducir junto con la belleza y la estructura del texto. Además, la ambigüedad no sólo es la base de la belleza y la configura, sino que constituye el espacio en el que el autor se esconde y se desvela.

Umberto Eco esclareció la noción ambigüedad con particular acierto, aunque no fuera propiamente en el campo de la traducción. Antes de intentar adecuar su reflexión a la traducción, veamos con más detenimiento qué opina.

Para Eco la comunicación es ante todo un proceso. Este proceso implica un sistema, por lo tanto una estructura, la de la lengua junto con la de la cultura en sentido general; y la cultura debe ser estudiada como fenómeno de comunicación. Eco aporta aquí una contribución personal que consideramos particularmente interesante, al considerar que este fenómeno no es necesariamente el resultado de un intercambio entre varios individuos, sino más bien una habi- 


\section{BELLEZA Y ATRACCIÓN EN TRADUCCIÓN LITERARIA}

lidad mnemónica que permite a una persona, incluso sola, recurrir a la cultura, a la lengua. Eco dice que la semiótica estudia todos los procesos culturales en cuanto procesos de comunicación y que tiende a mostrar cómo, bajo los procesos culturales, existen unos sistemas. La dialéctica sistemaproceso se traduce así en dialéctica código-mensaje.

Encontramos en esta reflexión varios elementos del estructuralismo esbozado por Saussure aunque con un nuevo acento puesto en la dialéctica, que pronto llevará a las oposiciones binarias en las que se basa la informática. Pero lo que diferencia a Eco de Saussure es la importancia que Eco le otorga a la teoría de la comunicación. Al conjunto de combinaciones de Saussure, Eco añade conceptos como el ruido: "El ruido es una perturbación que se introduce en el canal y puede alterar la estructura” (1994:45), explica, sin preguntarse sin embargo si una estructura existe por sí misma, definiéndola más bien como un modelo operatorio construido mediante operaciones simplificadoras que permiten uniformizar fenómenos diversos desde un mismo punto de vista. Además, el código es considerado como un sistema de probabilidad, lo que permite a Eco introducir la interesante cuestión de los automatismos. "Los mecanismos, los automatismos del lenguaje impulsarían al que habla a decir determinadas cosas y no otras. En este sentido, la verdadera fuente de la información, la reserva de información posible, sería el mismo código" (1994:65). Esta es una interesante apertura que va más allá de la simple distinción lengua-habla de Saussure -aunque en cierta medida sea su continuación- y que lleva directamente a una visión de la estética que podríamos utilizar para la traducción.

Eco, como Saussure, recurre a la imagen del ajedrez: el valor de cada pieza depende de la posición que ocupa con respecto a las demás piezas y cualquier perturbación del sistema transforma de forma correlativa el valor de las otras piezas. Lo que hace la imagen específicamente interesante en Eco es que podemos unirla a las nociones ruido y probabilidad, así como a lo que él denomina circunstancia. "Una bandera roja en una playa tiene un sentido totalmente distinto de una bandera roja agitada en una manifestación política”, (1994:129) así como en el ajedrez una reina aislada no significa lo mismo que una reina rodeada de peones.
El ruido, la probabilidad, la circunstancia, son elementos de una ambigüedad que está en la base del mensaje estético, estructurada de tal forma que lo que rodea la cosa contribuye, tanto como la cosa misma, en la configuración de la belleza.

Si Eco ha llevado más lejos el pensamiento estructuralista desarrollado por Saussure es, sin duda, para articularlo mejor con la teoría de la comunicación, pero también para desarrollar el concepto mensaje estético, poco tratado por Saussure, del que Eco manifiesta lo siguiente:

El mensaje reviste una función estética cuando se estructura de una manera ambigua y se presenta como autoreflexivo, es decir, cuando pretende atraer la atención del destinatario sobre la propia forma, en primer lugar. [...] Un mensaje totalmente ambiguo resulta extremadamente informativo" (1994: 138).

Desarrollar el pensamiento estructuralista para reflexionar sobre la ambigüedad como modo de comunicación en primer lugar (incluyendo, como dice Eco, cuando el proceso es en parte inconsciente) y como vehículo de la estética después, es muy seductor y susceptible de ser adaptado a la traducción, particularmente a la traducción de la forma, a la traducción literaria.

Eco indica que el mensaje ambiguo es rico en informaciones puesto que ofrece numerosas opciones interpretativas. Sin embargo, esto puede acercarse al ruido, es decir, al simple desorden. Quizá podríamos hablar de interpretación abierta en el caso de la poesía y de desorden en el caso de la poesía experimental. La única divergencia con vistas a la traducción sería una diferencia de niveles de dificultad en la elección de la interpretación. En el caso de la poesía (incluida la literatura poética, o la poesía en prosa), los significantes adquieren significados apropiados únicamente por interacción contextual. Toman un significado determinado a la luz del contexto, quedando cargados de las otras opciones posibles. Así pues, son precisamente estas otras opciones posibles las que hacen delicada la traducción y, sobre todo, muy interesante. 


\section{Natalia Arregui Barragán y Louis Jolicœur}

Entreculturas 11 (2021) pp. 36-52

Esta ambigüedad semántica está combinada con cierto juego de formas. De hecho, si el sentido es deliberadamente ambiguo, el estilo y la forma de las frases de un autor también tienen un sentido, ya que las diferentes partes de una estructura están siempre estrechamente ligadas.

Esto nos interpela la obra La ausencia del premio Nobel austriaco Peter Handke ${ }^{12}$ donde la ausencia, tiene un sentido. En su momento muy apreciada por la crítica, bien escrita (al menos por lo que la traducción nos permite juzgar), esta novela de estilo sobrio no plantea, a primera vista, mayores dificultades. Sin embargo, una lectura profunda puede llevar al lector a un terreno que la apariencia casi simplista de la historia no le habría hecho ni sospechar. El lector queda abocado a la irritación, a la frustración; sobre todo aquel lector que haya tenido la idea, muy legítima en sí, de buscar entre líneas al autor de esta curiosa novela.

Por otro lado, en poesía, la materia de la que están hechos los significantes no aparece como arbitraria con respecto a los significados y a su relación contextual (el caso extremo sería, por supuesto, la rima). Y si la forma tiene así un sentido, la substancia de la expresión adquiere también una forma. Tanto que se puede situar en un mismo plano el contenido y la forma, y ver el mensaje estético como algo que puede poner en juego diversos niveles de realidad que Eco divide de la siguiente manera:

\section{[...] el técnico y físico de la substancia de que se com- ponen los significantes; el de la naturaleza diferen- cial de los significantes; el de los significados deno- tados; el de los distintos significados connotados; el de las expectativas psicológicas, lógicas, científicas a las que remiten los signos (1994: 140).}

De esta categorización de Eco, podríamos decir que si el traductor literario consigue identificar estos niveles (claro que no es necesario que sea de una manera tan esquemática), y articularlos después a un único código general que los

12 Peter Handke, La ausencia, traducción de Eustaquio Barjau, Madrid, Alianza, 1993. estructura todos, entonces, quizá podrá traducir. Después tendrá que reproducir en otra lengua este sutil andamiaje de niveles, buscando una ambigüedad cuyo efecto se corresponda, aunque no necesariamente a cada nivel.

Al concepto nivel de realidad, Eco agrega lo que denomina la co-realidad, que sería una información estética global que no se realiza en ninguno de los niveles particulares que acabamos de mencionar. Se trataría de cierta esencia, "que no sería otra cosa que la belleza" (1994: 143) plasmada en el mensaje pero imposible de determinar con herramientas conceptuales.

Este mensaje estético se realiza generalmente transgrediendo la norma (lo que los formalistas rusos denominan efecto de extrañamiento) de ahí la estructura ambigua. Pero aunque podemos comentar con Eco que la belleza se encuentra muy a menudo donde se transgrede la norma, la norma transgredida no implica, al contrario, automáticamente belleza. La transgresión por sí misma no basta para localizar, analizar y traducir después el mensaje estético. El traductor podrá intentar reproducir la estructura estética del mensaje buscando el enigma de la forma y del contenido y teniendo en cuenta después los niveles anteriormente señalados. Debe así reconstruir estos niveles en una estructura parecida, ya que la belleza será recreada en la medida en la que el traductor sepa mantener un equilibrio tan bien dosificado como el equilibrio original y cuya forma esté tan alejada de la norma como lo está la forma del texto origen. Hablamos de belleza recreada dando por hecho que hay belleza en el texto origen, a menos que sea creada a partir de cero, pero nos deslizamos en el terreno de la delicada cuestión de la mejora del texto.

Es evidente que este proceso no se da en cada palabra sino en un registro mucho más global, en la propia estructura del texto. No hay duda de que el fenómeno es a menudo inconsciente, ya que los traductores, en el momento de traducir, poco inciden sobre combinaciones o estructura, aunque el estilo, que siempre hay que tener presente, contrariamente a estos conceptos más teóricos y abstractos, sea un claro componente de la estructura del texto.

Aunque la cuestión de la definición de la belleza es importante (con la dificultad que conlleva), su pertinencia 


\section{BELLEZA Y ATRACCIÓN EN TRADUCCIÓN LITERARIA}

en estas páginas no es intrínseca: la belleza no es tratada por lo que es o puede ser, sino en virtud del interés que debe tener el traductor por reproducirla. De este modo, tras haber intentado definir la belleza en tanto concepto, conviene centrarse en la estructura de lo bello desde la perspectiva de su eventual reproducción. Escuchemos de nuevo a Eco sobre la posibilidad de reproducir la información estética:

\begin{abstract}
Al estructurarse de modo ambiguo respecto al código y transformando continuamente sus denotaciones en connotaciones, el mensaje estético nos impulsa a identificar en él códigos siempre distintos. En tal sentido, en su forma vacía hacemos confluir significados siempre nuevos, controlados por una lógica de los significantes que mantiene tensa la dialéctica entre la libertad de interpretación y la fidelidad al contexto estructurado del mensaje (1994:152).
\end{abstract}

El razonamiento de Eco sobre la dialéctica entre fidelidad al mensaje y libertad de interpretación no está dirigido hacia la traducción, pero no cabe duda de que abona bien el terreno. Citemos también su reflexión sobre la comprensión del mensaje estético:

La comprensión del mensaje estético se funda también en una dialéctica entre aceptación y repudio de los códigos y léxicos del emisor, por un lado, y la introducción o rechazo de los códigos y léxicos personales, por otro (1994:155).

Siguiendo los pasos de Eco, es legítimo proponer que la dialéctica también puede existir entre forma y apertura -en lo referente al mensaje- y entre fidelidad e iniciativa -en cuanto al destinatario-, marco en el que se da el proceso de descodificación, o la actividad interpretativa (el acto de traducción), que puede ir desde un máximo de azar a un máximo de fidelidad. El azar se produce cuando el significante se remite a códigos arbitrarios y la fidelidad se impone cuando se establece una dialéctica continua entre los códigos del destinatario y los códigos de la emisión.
La estructura no pertenece a la categoría de la observación empírica: se sitúa más allá y constituye un sistema regido por una cohesión interna. No podemos descubrir esta cohesión observando un sistema aislado, ya que sólo se revela al estudiar transformaciones, gracias a las cuales encontramos propiedades similares en sistemas aparentemente diversos. Esta consideración se manifiesta todavía más determinante cuando reflexionamos sobre la traducción literaria, o, si se prefiere, sobre la traducción del mensaje estético: el estudio de las transformaciones tiene muchos puntos en común con la forma en la que nosotros aprehendemos el concepto efecto, ya que éste está precisamente definido por un conjunto de elementos (el tono, el ritmo, la musicalidad ${ }^{13}$, la presencia del autor, su época, su corriente, etc.) que constituyen una cohesión interna que no puede, de ninguna manera, limitarse a un sistema aislado.

Destaquemos otro pasaje de Eco en el que la ambigüedad además de ser percibida como indispensable para el mensaje estético, también va asociada a una necesidad aún más fundamental: la de comunicar, donde la belleza deja de ser un lujo para convertirse en una necesidad, y la cuestión se aleja de las esferas estrictamente semióticas para ser garante de la defensa del arte:

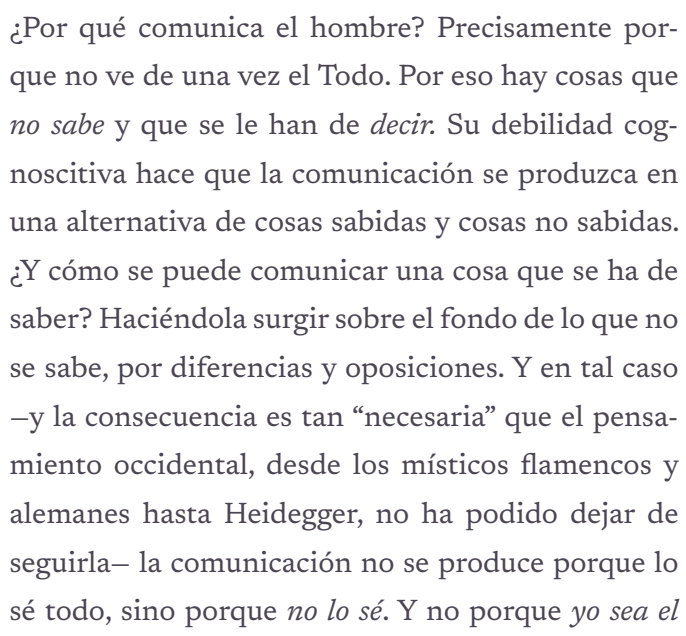

13 Jean Paul Sartre habla incluso del gusto de una frase en la obra ¿Qué es la literatura? traducción de Aurora Bernárdez, Madrid, Losada, 2003, p.62, o de su fisionomía en la página 88. 


\section{Natalia Arregui Barragán y Louis Jolicœur}

Entreculturas 11 (2021) pp. 36-52

todo (como Dios) sino porque yo no soy Dios. Lo que me constituye como hombre es mi no ser Dios, el hallarme separado del ser, el no ser la plenitud del ser. El hombre ha de comunicar y pensar, y elaborar un acercamiento progresivo a la realidad, porque es defectuoso, porque le falta algo. Tiene una Carencia, una herida, una béance, un Vacío (1994:375).

Señalemos también las palabras de Sartre (2003: 63) sobre el significado, en este caso, el significado del siguiente verso de Rimbaud: O saisons! O châteaux! Quelle âme est sans défaut?: "Sería absurdo creer que Rimbaud 'ha querido decir': todos tienen sus defectos. Como decía Breton de Saint-Pol Roux: 'Si hubiese querido decirlo, lo hubiera dicho'. Y tampoco ha querido decir otra cosa. Ha formulado una interrogación absoluta; ha otorgado a la hermosa palabra alma una existencia interrogativa. He aquí la interrogación convertida en cosa [...] Ya no es una significación; es una substancia; está vista desde fuera y Rimbaud nos invita a verla desde fuera con él, su extrañeza procede de que nosotros nos colocamos para considerarla del otro lado de la condición humana, del lado de Dios".

Dejando de lado la cuestión de la evocación a Dios (proviniendo de Sartre, sería legítimo ver en ella un lugar, una posición más que un concepto metafísico), es interesante confrontar las reflexiones de Sartre y de Eco sobre el significado. Para Sartre, más allá del significado está la substancia, que puede ser observada desde fuera. Para Eco, sin embargo, este fuera sería una posición inaccesible (el hombre no puede ver de una vez el Todo), carencia que contribuye a que la comunicación sea posible. Podría ser interesante proponer una visión intermedia, a la Foucault (que sin embargo aquí se acerca más a Eco que a Sartre), en la que el fuera no es ni el punto etéreo del que se mira, ni la expresión de una carencia inaccesible, sino el punto que se mira, que nos interpela, nos atrae y nos estimula.

Y la belleza atrae, por ello opinamos que el concepto belleza tiene una enorme importancia en traducción, ya que en última instancia hay que respetar un sentido, un mensaje, un efecto, y legitimar las diferentes elecciones (incluso si a menudo se hacen sólo con uno mismo). Pero mejor que tomar el camino ético-metafísico conducente a esta verdad, podemos ver en la belleza una moral de la intervención más que una moral que oponga un bien a un mal; y en la verdad, más allá de la subjetividad y en una perspectiva más fenomenológica que sicológica, un elemento suplementario en la configuración del deseo de lo bello, un elemento, por tanto, que contribuye finalmente a la atracción.

\section{LA ATRACCIÓN}

El concepto atracción, tal y como lo ha fomentado Michel Foucault en una obra dedicada a Maurice Blanchot ${ }^{14}$, prolonga el de belleza que acabamos de presentar, permitiéndonos desarrollar una herramienta que puede adaptarse perfectamente a la traducción.

La atracción, para Foucault, es ante todo una invocación. Como lo es para Sade el deseo, para Nietzsche la fuerza, para Artaud la materialidad del pensamiento, para Bataille la transgresión: la experiencia pura y más desnuda del afuera ${ }^{15}$.

Veamos en primer lugar un pasaje de Foucault en el que expone su concepto atracción que enlaza estrechamente con el afuera:

Ser atraído, no consiste en ser incitado por el atractivo del exterior, es más bien experimentar, en el vacío y la indigencia, la presencia del afuera, y, ligado a esta presencia, el hecho de que uno está irremediablemente fuera del afuera. Lejos de llamar a la interioridad a aproximarse a otra distinta, la atracción manifiesta imperiosamente que el afuera está ahí, abierto, sin intimidad, sin protección ni obstáculo (¿cómo podría tenerla, él que no tiene interioridad, sino que la despliega al infinito fuera de toda clausura?); pero que a esta abertura misma, no es posible acceder, pues el afuera no revela jamás su esencia;

14 Michel Foucault, El pensamiento del afuera, traducción de Manuel Arranz, Valencia, Pre-textos, 2000.

15 Id., ibid., p.33. 


\section{BELLEZA Y ATRACCIÓN EN TRADUCCIÓN LITERARIA}

Entreculturas 11 (2021) pp. 36-52

no puede ofrecerse como una presencia positiva -como una cosa iluminada desde el interior por la certidumbre de su propia existencia- sino únicamente como la ausencia que se retira lo más lejos posible de sí misma y se abisma en la señal que emite para que se avance hacia ella, como si fuera posible alcanzarla (2000: 33-34).

Para Foucault la atracción es, en primer lugar, el hecho de experimentar la presencia del afuera, lo que podríamos relacionar con el sentimiento experimentado en la lectura de un texto que nos invoca y nos estimula (que, en consecuencia, generalmente nos gustará), y en segundo lugar el hecho de encontrarse "irremediablemente fuera del afuera”, es decir: irremediablemente en situación y ante el deber de interpretar ese texto.

Joyce decía dando así una excelente definición de una lectura invocadora: "No creo en ninguna ciencia, pero mi imaginación se anima cuando leo a Vico, lo que no me ocurre con Freud o Jung ${ }^{16}$."

Es cierto que cabría preguntarse si no hay contradicción entre el enfoque que mostramos y el pensamiento de Foucault, cuando éste afirma que "lejos de llamar a la interioridad a aproximarse a otra distinta, la atracción manifiesta imperiosamente que el afuera está ahí". O incluso cuando mantiene que el afuera no tiene interioridad ya que está infinitamente abierto. De hecho, se antoja difícil conciliar esta no-aproximación (entre un traductor y un autor) y esta ausencia de interioridad (del texto que hay que traducir), con la propuesta de identificar este autor con el texto, y el traductor con el propio autor. Pero detengámonos en estas consideraciones; primero la cuestión de la aproximación y después la de la ausencia de interioridad.

$\mathrm{Al}$ estudiar en profundidad el pensamiento de Foucault podríamos hacer el siguiente análisis: si la consecuencia de la atracción no es aproximar la interioridad de uno (el traductor) y de otro (el autor) sino solamente manifestar el

16 Richard Ellmann, James Joyce, Oxford, Oxford University Press, 1977. La traducción es nuestra. afuera (el texto), ¿qué es esta manifestación? ¿No se trata precisamente de convertir el objeto en algo localizable, en una entidad que pueda continuar ofreciendo, que no revelando, su esencia? Si es así, es lo que busca el traductor.

En realidad, no es la aproximación en sí lo que interesa en el campo de la traducción sino más bien el resultado: manifestar un texto de forma que se reproduzca un efecto constituido por múltiples elementos textuales y del autor. En el fondo, la aproximación real con el autor no es muy útil, incluso a menudo es perjudicial ya que la atracción puede verse muy alterada al estar fundada precisamente, como bien indica Foucault, en la ausencia. Además, el contacto continuo, la familiaridad, incluso la amistad con el autor, aspiración legítima por parte de un traductor seducido por una obra, pero cuya materialización, es, reconozcámoslo, a menudo decepcionante, hace que el mensaje que el traductor tiene la misión de manifestar pueda ser filtrado y modulado de forma considerable.

Reiteramos que el autor al que aquí proponemos traducir en la misma medida que el texto poco tiene que ver con la persona física del autor. Lo que interesa al traductor es el escritor en tanto creador de un texto ${ }^{17}$, no el individuo cuya personalidad y discurso pueden contradecir totalmente la obra e incluso inspirar respeto al traductor, admiración o cualquier otro sentimiento que puede provocar que falsee la interpretación que este debe hacer del texto.

Ya que si la atracción es el motor de la traducción, si el placer -de leer y traducir después- puede ser una garantía de calidad, hay que precisar que este placer está ligado al deseo de comprender un texto y, a través de él, a un autor, con el objetivo de prendarse y hacer que se prendan tanto del uno como del otro. Es decir que tenemos por un lado la atracción que ejerce un texto origen y que se convierte en el motor de la traducción y, por otro lado, el placer de traducir un texto para aproximarnos a un autor y revelarlo a los demás.

17 Para el desarrollo de esta cuestión les proponemos la lectura de la obra ApreHendiendo al leer: Eduardo Mendoza y la traducción literaria (manual para el traductor novel) de Natalia Arregui. Granada: EUG, 2009. 
La imposibilidad de aproximación entre dos interioridades, como la formula Foucault, es una consideración que al analizarla no se opone a la idea de traducir al autor así como al texto, y que contribuye a delimitar mejor la noción atracción que nos interesa.

La segunda consideración atañe a la cuestión de la ausencia de interioridad. Es cierto que significa que el acceso al afuera es esencialmente imposible; pero, precisa Foucault, de tal manera que se emite una señal como si fuera posible alcanzar esta ausencia. De esta forma, como en el caso anterior, más que ver en la ausencia de interioridad la no-pertinencia de la voz que sirve de base al texto y donde se esconde, podríamos asociarla a la ausencia aparente del autor, la que permite al lector insertarse en el texto e intervenir, a través de él, con el autor.

Bajo este prisma, la no-interioridad del afuera no elimina en absoluto al autor, más bien siguiendo nuestra proposición, contribuye a que se establezca un lazo (y no un acercamiento real, recordémoslo) entre el traductor y el autor que traduce en su texto, un lazo febril, movedizo, tanto más eficaz cuanto parcial, progresivo y siempre por construir.

De este modo, en virtud del análisis planteado, sería legítimo acoplar a la traducción el pensamiento de Foucault y considerar el objeto que hay que traducir como una invitación a la que el lector-traductor debe responder. En primer lugar invitación a la lectura, después a la relectura y por último a la reproducción. Invitación del texto y después del autor que se oculta en él.

La respuesta dada a este ofrecimiento debe ser muy rigurosa. Y para conseguir este rigor, el traductor debe reconstruir una forma (hablemos de coherencia más que de interioridad y puntualizando, de la nueva coherencia del texto traducido), así como una estructura evocadora susceptible de atraer a los lectores en lengua meta como fueron atraídos los lectores en lengua origen.

Ha llegado el momento de explorar más a fondo los mecanismos propios de la atracción.

El origen de la atracción que experimenta el lector-traductor se encuentra en la invocación que emana del texto que hay que traducir. La interacción entre el texto en cuestión y el lector-traductor constituye el motor de la traducción.
En este aspecto la traducción no es muy diferente de cualquier otra forma de interacción entre un objeto y quien se siente atraído por él. La invocación de la que aquí hablamos, unida a las ausencias del objeto, se encuentra, en menor o mayor medida, en toda obra de arte (contemporánea), sea literaria, pictórica, musical o de cualquier otro tipo. Veamos dos ejemplos: el arquitecto montrealés de origen rumano Dan Hanganu explicó (en marzo de 1993) en una conferencia ofrecida en el Museo de Québec que en toda obra, lo bello es la materia que se quita, es decir, la parte que falta, el vacío, más que lo que queda. No es bello simplemente por lo que se quita, sino que también lo que se quita es bello. En la misma línea, la escultora Laura Santini en la revista montrealesa Designs (diciembre de 1992) dijo:

\begin{abstract}
I have used a part to represent a whole. [...] In all my work I take away something and that gives both me and the viewer something to play with. [...] The challenge in manipulating parts and voids is to create a certain classical equilibrium.
\end{abstract}

Es la misma idea que hemos asociado al trabajo de traducir: las ausencias del texto permiten al otro -en este caso al traductor- intervenir en el proceso artístico, o, en lo que nos concierne, traducir; estas ausencias son las que constituyen el motor de la intervención, la atracción.

Una vez que se establece y mantiene el equilibrio resultante de esta interacción (entre el texto en cuestión y el lector-traductor), la traducción se convierte en un trabajo laborioso y minucioso, lúdico y creativo, así como abierto a la sensibilidad del traductor y a la lengua que constituye su material. De hecho, el traductor debe responder a la invocación del texto y del autor que en él se expresa, debe escuchar lo que se activa en él por su lectura y lo que vibra en su lengua: el efecto de las palabras, de las frases, de la lengua en su conjunto. Además, este trabajo que reúne atributos en apariencia tan opuestos se realiza entre otros dos extremos, que, de forma eminentemente solitaria, se ofrecen al traductor: la literaridad y la literalidad. Entre estas dos eternas posturas debe imponerse una vía intermedia; hay que insistir en lo que puede considerarse una eviden- 
cia, puesto que aunque en estas páginas invitamos a utilizar el concepto efecto en la evaluación del cómo traducir, y no tanto a discutir sobre la literaridad o la literalidad de una traducción, esta polarización epistemológica sigue existiendo en traducción, (lo vemos a diario en nuestras clases, aunque nos separa todo un océano), justificando por ende que siga siendo criticada.

Y sin ánimo de suscitar polémica alguna, lo que queremos que nuestro lector recuerde es que el vacío contribuye a la atracción y la imposibilidad es, en consecuencia, un motor más que una traba. En este contexto podemos decir que aceptar traducir es arriesgarse a lo imposible para inspirarse después en ello, es querer aproximarse respetando la distancia ineluctable con el único objetivo de conocer y transmitir.

Tras intentar adecuar el concepto atracción a la traducción, podemos afirmar que el trabajo del traductor proviene del deseo de responder a la invocación del texto que hay que traducir, lo que nos remite a una noción ya conocida: el placer -el de sentir la atracción y reproducirla después para permitir que otros la sientan-.

Esta dialéctica deseo-placer, que brota de un texto pero es creada por un autor, se encuentra y se desarrolla a lo largo de todo el proceso de traducción. Así pues, sin más compañía que el vacío de la atracción, la ausencia de referencias y los límites que le impone su propia perspectiva, el traductor necesita unas normas (¿quién se las impondrá?), una ética (¿cuál?). A falta de este marco, a menudo inexistente fuera de uno mismo, al traductor le queda el placer, pero éste conlleva también un peligro: el placer de la atracción puede embriagar y embarullar el sentido (común), sin hablar de la amenaza de identificación excesiva, de complacencia hacia el texto origen o, al contrario, de repulsión.

No cabe duda de que esta dialéctica deseo-placer comporta riesgos que el traductor sólo podrá sortear con su propio juicio y una preocupación constante por reproducir un equilibrio y un efecto que primero debe sentir y después querer reproducir; pero a pesar de la vaguedad que ello implica forzosamente sobre el plano epistemológico, pese a la dificultad ligada a la ausencia de criterios más objetivos y colectivos, podemos decir que cualquier teoría de la traducción que intentara eludir estos elementos para proponer una perspectiva más sistemática y científica la consideraríamos aún mucho más peligrosa. De hecho, el concepto atracción y la dialéctica deseo-placer constituyen la vía más segura hacia un trabajo de traducción serio, es decir: la mejor garantía de valor y de calidad de una traducción, puesto que la literatura como mensaje estético es por esencia movediza y está hendida, y los objetos literarios (las cosas descritas por la literatura), como toda expresión lingüística, son modificados por su propia enunciación (lo que Austin llama la fuerza ilocutoria propia de todo enunciado ${ }^{18}$ ) y se desarrollan en un devenir perpetuo.

Para concluir, decir que el trabajo del traductor debe considerarse en primer lugar como un acto de lectura, en absoluto pasivo, al que le secunda la tentativa -imposible en última instancia pero estimulante en su función heurística- ${ }^{19}$ de colmar la ausencia (para uno mismo) y crear un puente entre dos culturas (para los lectores en lengua meta). Una vez hecho esto, el traductor debe imponerse unas normas (hemos visto que seguramente tendrá que imponérselas él mismo), normas que deberá construir basándose en el autor que va a traducir, es decir, aprendiendo a conocerlo y deseando darlo a conocer. Normas que, por lo tanto, serán diferentes para cada autor traducido.

\section{REFERENCIAS BIBLIOGRÁFICAS}

Actes des quatrièmes assises de la traduction littéraire, Arles,

Actes Sud, 1988.

Arregui Barragán, Natalia (2009): ApreHendiendo al leer: Eduardo Mendoza y la traducción literaria (manual para el traductor novel). Granada, EUG.

18 John Langshaw Austin, How to do things with words, Cambridge, Harvard University Press, 1962. Subrayemos que Sartre, antes que Austin, se interesaba por la fuerza ilocutoria del enunciado, aunque utilizando una terminología diferente. Destaquemos este pasaje: “Hablar es actuar: toda cosa que se nombra ya no es completamente la misma; ha perdido su inocencia." (Jean Paul Sartre. ¿Qué es la literatura? traducción de Aurora Bernárdez, Madrid, Losada, 2003, p.68).

19 Barbara Folkart, "La fonction heuristique de la traduction", en Meta, vol.35, n¹, 1990, p.41. 


\section{Natalia Arregui Barragán y Louis Jolicœur}

Entreculturas 11 (2021) pp. 36-52

Austin, John Langshaw (1962): How to do things with words. Cambridge, Harvard University Press.

Balzac, Honoré de (1931): Le Chef-d'œuvre inconnu. Paris, Ambroise Vollard.

Barthes, Roland (1974): El placer del texto, traducción de Nicolás Rosa. Madrid, Siglo XXI.

Duras, Marguerite (1991): El amante de la china del norte, traducción de Beatriz de Moura. Barcelona, Tusquets.

Eco, Umberto (1994): La estructura ausente, traducción de Francisco Serra Cantarell. Barcelona, Lumen.

Ellmann, Richard (1977): James Joyce, Oxford, Oxford University Press.

Folkart, Barbara (1990): «La fonction heuristique de la traduction». Meta, vol.35, nำ1.

Foucault, Michel (2000): El pensamiento del afuera. Traducido del francés La pensée du dehors por Manuel Arranz. Valencia, Pre-textos.

Handke, Peter (1993): La ausencia, traducción de Eustaquio Barjau, Madrid, Alianza.

Lacan, Jacques (1966): Écrits I. Paris, Seuil.

Jolicœur, Louis (1985): Les adieux. París, Christian Bourgois, traducción de Los Adioses de Juan Carlos Onetti.

Jolicœur, Louis (1985): Le puits. París, Christian Bourgois, traducción de El pozo de Juan Carlos Onetti.

Kant, Emmanuel (1966): Le jugement esthétique. Paris, Presses Universitaires de France.

Mounin, Georges (1955): Les belles infidèles. Paris, Cahiers du Sud.

Ricœur, Paul (2001): Del texto a la acción. Ensayos de Hermenéutica II, traducción de Pablo Corona. Buenos Aires, Fondo de Cultura Económica.

Sartre, Jean Paul (2003): ¿Qué es la literatura? traducción de Aurora Bernárdez. Madrid, Losada.

Zecchi, Stefano (1990): La Bellezza. Turín, Bollati Boringhieri. Schiller, Friedrich, [En línea. Consulta: 10 de septiembre de 2020]: Cartas sobre la educación estética del hombre. Decimoquinta carta. http://www.antorcha.net/biblioteca_virtual/filosofia/schiller/15.html. 